\title{
A Process Perspective on Emerging Value in Tournament-based and Collaborative Crowdsourcing
}

\author{
Hee Rui He \\ Dalian Maritime University, China \\ hee.rui.he@dlmu.edu.cn
}

\author{
Julia Kotlarsky \\ University of Auckland, NZ \\ j.kotlarsky@auckland.ac.nz
}

\author{
Dorit Nevo \\ Rensselaer Polytechnic Institute, US \\ nevod@rpi.edu
}

\begin{abstract}
Value, in crowdsourcing, is attributed to outcomes such as reducing costs, improving quality through broad participation, generating alternate solutions with increased creativity, and enabling the employment of specialists on an ad-hoc basis. These benefits of crowdsourcing typically reflect the focal firm's perspective and are perceived at a single point in time, either prior to initiating the project or post-hoc. In this study we take a longitudinal and stakeholder-centered approach to examine the process of value (co-)creation through interactions between firm and crowd. We offer a process perspective on emerging value and distinguish between value for firm and value for crowd. In doing so, we close an observed gap in the literature which lacks an overarching understanding of crowdsourcing value creation.
\end{abstract}

\section{Introduction}

Crowdsourcing, which refers to the engagement of external crowd in projects via online crowdsourcing platforms [1] is gaining recognition for its contribution to value creation in organizations. This value is attributed to outcomes such as reducing time to market, reducing costs, improving quality through broad participation, generating alternate solutions with increased creativity, and enabling the employment of specialists on an ad-hoc basis [2].

The literature on value creation through crowdsourcing is still in its infancy, and somewhat fragmented. Some papers focus on the ability of the crowd to generate value, for example, by studying whether crowd members can compete with professionals in new product development ideas [3]. Other examples consider crowdsourcing as enhancing the competitive ability of lean start-ups [4], or enabling organizations to compete with ordinary resources [5].

At a higher level, Kohler [6] studied crowdsourcingbased business models to explore how value is created by each model. Analyzing crowdsourcing business models at varying levels of success, he addresses specific challenges to value creation and prescribes actions for organizations. This higher level of analysis of the business value of crowdsourcing is useful in that it can be generalized over different crowdsourcing settings. In this paper we take a similar path toward a more generalizable examination of value creation in crowdsourcing. Specifically, we take a stakeholders' approach to value generation, and we focus on the process of value creation through interactions between a project's stakeholders. This approach is motivated by a desire for a deeper understanding of the unique value that crowdsourcing can provide both firms and crowd members in comparison to other sourcing models. Specifically, while expected outcomes of productivity and creative ideas (for the firm) or monetary rewards and accomplishments (for the crowd) can also be associated with other sourcing models, we are interested in the distinctive value that is created through unique features of crowdsourcing. In this work we study in depth two crowdsourcing forms: tournament-based and collaborative, and we elicit value beyond what is typically expected. Further, we follow one crowdsourcing project over time. We believe that taking a longitudinal approach can provide a temporal perspective on emerging value and distinguish between value for firm and value for crowd. In doing so, we address an observed gap in the literature which lacks an overarching understanding of crowdsourcing value creation process.

\section{Theoretical Background}

Three value related constructs provide the necessary backdrop for our work. The first two originate in the marketing literature and concern the economic meaning of value: value-in-exchange occurs when value is created by the firm and distributed in the market (i.e. through exchange of goods and money); value-in-use implies that value is continuously co-created through interactions between firms and customers [7]. The third construct comes from the IS literature and concerns the business value of IT. It considers the performance impacts of information technology in terms of efficiency and competitiveness [8]. Taken together these value definitions imply three key actors are involved in the creation of value: the firm, the customers, and the 
technology artifact. In this work we examine a fourth value creating actor in the form of the sub-contractor, which, in the case of crowdsourcing, is represented by the crowd.

Depending on the specific crowdsourcing model employed, the crowd can play different roles in creating value. In Wikipedia, for example, the crowd's role is similar to that of the firm, generating value-inexchange: crowd members create content, which is then consumed by Wikipedia readers. In Threadless, the crowd's role is similar to that of consumers generating value-in-use by generating and evaluating designs in a series of interactions among themselves, or with the platform. Finally, Kohler [6] discusses a product platform crowdsourcing business model that aligns with the business value of IT. Here, creators build on to a technology or a basic product and sell the resulting products to customers. This is an example where value creation can be attributed to interactions between the crowd and the technology platform, highlighting its business value.

Our work proposes a different view of these three value types by examining interactions among them. When crowd members perform a specific task contracted out by the firm, part of the value is created in the exchange, through the creation of the desired deliverables (e.g. [9]). Additional value is created in use, through interactions that are shared between the company and the crowd (e.g. [10]). And yet additional value is created through the features of the technology platform. This calls for new models and strategies of value creation and capture, to account for the contribution of all valuecreating participants [6]. Hence, the first objective of our work is to study the process of value creation, specifically, how value is co-created by stakeholders over the life of the crowdsourcing project.

A second foundational literature that we examined concerns specific benefits that both firms and crowd expect to obtain through crowdsourcing participation. From the firm's perspective, crowdsourcing has been shown to contribute both tangible and intangible values. For example, Poetz and Schreier [3] compared the quality of ideas generated by a firm's professionals to those submitted by users in an idea generation contest. They found that the best ideas were concentrated among users rather than professionals. Similarly, Nishikawa et al. [11] show that labeling crowdsourced new products as such increases the product's actual market performance by up to $20 \%$, and that this effect can be attributed to perceptions of increased quality perceptions. Additional examples of tangible benefits include increased accuracy and performance (e.g. [12][13]), lower costs, and reduced time to solution (e.g. [14][15]). Intangible benefits include the ability to leverage outside capabilities and skills, increased knowledge diversity, understanding of customer preferences, and externalization of project risk (you only pay for results you are happy with) [15]. Further, crowdsourcing may result in unexpected outcomes that can provide opportunities for the firm and generally positive effects [16].

From the crowd's perspective, insights on expected value can be obtained through literature on crowd members' motivation to participate and contribute to crowdsourcing projects. Studies here explore extrinsic motivation factors, such as career opportunities, payment, and personal need for innovations [17][18]. Morgan and Wang [19], for example, describe one contributor who was having a hard time finding a job in R\&D. Participating in an innovation challenge provided him with a $\$ 25 \mathrm{~K}$ reward as well as re-affirming his confidence in himself. Beyond extrinsic motivation, intrinsic factors are also important for participation. Such factors include the fun and enjoyment of developing solutions and satisfying intellectual curiosity [18], feelings of pride and respect [20], having a flexible work environment and job autonomy, working on varied tasks, and experiencing personal growth [17]. The above benefits of crowdsourcing are perceived at a single point in time, either prior to the project start or after its completion. What is missing from this literature is a more continuous view of project value as it unfolds. Therefore, our second objective is to add a temporal dimension to this body of literature and to track specific value outcomes as they unfold over the life of the crowdsourcing project.

To address these two objectives, we conducted a longitudinal qualitative case study following a crowdsourcing project by one of the leading Chinese escape room gaming houses.

\section{Research method}

This inductive theory-building research was designed as an in-depth longitudinal qualitative study of a crowdsourcing project. The first author spent 2.5 months at the case site following the project from its inception in June 2016 through to completion in August 2016. The project was subsequently tracked until implementation of the final outcome in 2017. We collected process data [23, 24] that focuses on understanding interactions and engagement between the firm and crowd actors; specifically, how they interact and what value they experience as they interact.

\subsection{Data collection and analysis}

Data for this study was collected from multiple sources, including: 1) interviews; 2) internal company and online documents; 3 ) direct observations (e.g. daily operations and weekly team meetings); and 4) informal 
conversations with members of the PM team. We conducted 12 formal interviews with three members of the Games Company, spanning over multiple milestones throughout the project lifecycle. Each interview lasted for 45 minutes on average. We also interviewed 3 winners when the project was completed. Each interview lasted for 60 minutes on average. In total, over 720 minutes formal interviews were recorded. In addition, the first author was on site at the GamesCo. Recorded documents included online working logs on the platform, documents provided by the focal firm, important information collected via informal chats and observations, snapshots of 15 collected game designs and meeting minutes. In total, over 120 pages of documents were collected. Overview of the data sources and list of the interviewees, their roles, and interview contents are summarized in Tables 1 and 2 , accordingly.

Table 1. Data Sources

\begin{tabular}{|l|l|}
\hline Interview & $\begin{array}{l}12 \text { formal interviews with } 3 \text { members of the focal firm. } \\
3 \text { formal interviews with } 3 \text { crowd members. }\end{array}$ \\
\hline Observation & $\begin{array}{l}\text { Daily observations spanning } 13 / 06 / 16-24 / 07 / 16 . \\
\text { Informal chats with } 3 \text { members of the focal firm during } \\
\text { observations. }\end{array}$ \\
\hline Documentation & $\begin{array}{l}\text { Online documentation on the platform. } \\
\text { Offline documentation recorded by the members of the focal firm. }\end{array}$ \\
\hline
\end{tabular}

Table 2: The List of Interviewees

\begin{tabular}{|c|c|c|}
\hline Interviewee & Role & Interview content \\
\hline Vincent & $\begin{array}{l}\text { - Top manager } \\
\text { - Game designer and market researcher on } \\
\text { the internal design team. } \\
\text { - Member of the PM team. }\end{array}$ & \multirow{3}{*}{$\begin{array}{l}\text { Weekly interviews } \\
\text { with each member } \\
\text { of the PM team. } \\
\text { Interviews focused } \\
\text { on: } \\
\text { - Project preparation, } \\
\text { initiation. } \\
\text { - Deliverable reviews } \\
\text { 1st, } 2 \text { nd and 3rd } \\
\text { weeks. } \\
\text { - Online and offline } \\
\text { phases }\end{array}$} \\
\hline Max & $\begin{array}{l}\text { - Top manager } \\
\text { - Game designer and market researcher on } \\
\text { the internal design team. } \\
\text { - Member of the PM team. }\end{array}$ & \\
\hline Joe & $\begin{array}{l}\text { - Store manager } \\
\text { - Game designer and engineer on the } \\
\text { internal design team. } \\
\text { - Member of the PM team. }\end{array}$ & \\
\hline The Gamer & $\begin{array}{l}\text { - One of the three winning online crowd } \\
\text { members (submission \#4) } \\
\text { - One of the two winning offline crowd } \\
\text { members }\end{array}$ & $\begin{array}{l}\text { - Online and offline } \\
\text { phases }\end{array}$ \\
\hline $\begin{array}{l}\text { The } \\
\text { Historian }\end{array}$ & $\begin{array}{l}\text { - One of the three winning online crowd } \\
\text { members (submission \#5) }\end{array}$ & - Online phase \\
\hline $\begin{array}{l}\text { The } \\
\text { Musician }\end{array}$ & $\begin{array}{l}\text { - One of the three winning online crowd } \\
\text { members (submission \#8) } \\
\text { - One of the two winning offline crowd } \\
\text { members }\end{array}$ & $\begin{array}{l}\text { - Online and offline } \\
\text { phases }\end{array}$ \\
\hline
\end{tabular}

In our data analysis we relied on temporal bracketing and visual mapping approaches [23], recommended for process decomposition and representation by Langley [24] and employed Gioia's methodology [25] to concept development. Before embarking on with-case analysis, multiple sources of data were integrated and organized in a chronological order to reflect the lifecycle of the crowdsourcing project. According to Gioia's methodology [25] the first order analysis focused on established concepts (e.g. monetary rewards, learning about the industry, two completed designs) directly from original transcripts. In the second order analysis, we tried to gain thorough understanding towards the investigated phenomenon from the perspective of informants, and then carefully translated it into the perspective of researchers. The first order concepts were associated with themes summarized from the literature review (e.g. value-in-use, value-in-exchange). During the third order analysis, the second order themes were aggregated into dimensions (e.g. expected value, emergent value and realized value). We then followed the guidance for the process theory development [24] to structure identified concepts, themes and dimensions.

\subsection{Game Design Project: Background}

3.2.1. Background on the GamesCo and local market. The field of live escape room games is relatively young but fast-growing within China's entertainment industry. An escape room gaming venue provides players with a locked adytum, a storyline, and a series of well-designed puzzles and tricks. The basic game principle is that a group of players follow the storyline and solve the puzzles and tricks in order to get out of the room. Established in 2013, GamesCo is one of the most successful entertainment companies in the local escape room market in China. At the time of data collection it had three stores employing about 45 people and containing 15 gaming rooms, and an annual revenue of more than 3,000,000 CNY.

As an early entrant to the field, GamesCo competitive advantages spans investments, game design, human resources, and brand awareness. It was ranked the \#1 escape room gaming house by local consumers and had accumulated very positive feedback on mainstream consumer-oriented commentator websites. To maintain their competitive edge the two co-investors, Vincent and Max, who held the top management roles in GamesCo, started thinking about new game designs. As managers, they believed that advanced technologies (e.g. 3D effects, artificial intelligence and virtual reality) and facilities (e.g. lighting systems, acoustic effects and operational machineries) are crucial to enhance the consumer's experience.

\subsubsection{Background of the Game Design} crowdsourcing project. Initially, GameCo intended to design the new games internally. The company had an design team comprising of professional game designers, market researchers and engineers able to conduct the entire game design process, including market research, theme and storyline design, puzzles and tricks design, and gaming room construction planning. Apart from its own game designs, the GamesCo purchased copyrights from an American entertainment company as an additional source of game designs. 
Of the existing 15 gaming rooms, eight were designed by the internal team, and the rest were modified from purchased packages. However, during a design team meeting, Max came up with the idea of crowdsourcing. The team agreed with the suggestion, realizing that interesting new game designs might be found at a relatively low cost.

The major purpose of the crowdsourcing (CS) project was to collect ideas for escape room game designs from the crowd. As Vincent explained, "The starting point is the most difficult [...] A promising idea is all we need." In seeking promising ideas, the team also took knowledge protection issues into consideration. On the selected crowdsourcing platform, it was expected that winning ideas will be made public as evidence of fairness and transparency. It would therefore be possible for industry competitors to see and take advantage of these ideas. After several rounds of discussions, the team clarified that they should not expect complete game designs from the crowd, but rather promising ideas worthy of further development ${ }^{1}$. With this in mind, the firm advertised on the CS platform ${ }^{2}$, specifying escape room game designs with interesting themes, storylines, and three to five embedded puzzles and tricks. It was agreed that after the winning ideas were chosen, the internal team would further develop promising ideas offline with the winning participants. The firm set a three-week period during which time it accepted bids from the crowd. Finally, the amount of prize money offered as reward was much higher than the market average level, in an attempt to attract more highquality submissions. For the first, online phase of the project, each of the three winners would receive a prize of 1,500 CNY. The second, offline ${ }^{3}$ phase of the project offered another 1,500 CNY for each winner.

The quality of the deliverables would be judged by the project management (PM) team members based on the story themes, storylines, tricks and puzzles designs, estimated construction difficulties, estimated budget, and other concerns. The team expected to find at least two high-standard deliverables from the online phase of the competition, which could then hopefully be developed into two sophisticated game designs through offline cooperation.

\footnotetext{
${ }^{1} \mathrm{~A}$ complete game design consists of one theme with storylines, 10 to 15 puzzles and tricks, and a construction plan. The creation of an interesting story theme with storylines and embedded puzzles and tricks are the most creative and challenging aspects of game design. A theme, with its accompanying storylines, has to be very engaging in order to trigger consumer interest. Usually, the GamesCo selects upto-date and popular story themes. Storylines, as containers of puzzles and tricks, elaborate how the story unfolds. Well-designed puzzles and tricks had to be gripping, logical, highly playable and with appropriate levels of difficulty (not so simple as to reduce playability, and not so
}

3.2.3. Management of the Game Design project. The management team for the CS project comprised three members: Vincent, Max and Joe, all of whom were involved in design and construction of the previous 15 game rooms. They also had definitive roles in the internal game design team. They agreed to make decisions jointly during weekly meetings.

The project was advertised as a tournament CS project with guaranteed rewards for the three top designs. At the end of the online phase, the PM team decided on the winning entries and authorized payment to the three winning crowd members. These were: the Gamer, the Historian and the Musician. During the second, offline phase of the project, GamesCo involved two crowd members in their internal game design processes. The internal design team engaged with and worked closely with the Gamer and the Musician (separately) to further develop their winning game designs into final products - physical escape rooms.

In the next section, we present our findings and analysis of interactions between GamesCo and the crowd members with intention to capture the emerging value, as perceived by the focal firm and crowd members.

\section{Findings and analysis}

The actions of the Game Design PM team and their interactions with crowd members were driven by the expected outcome - two promising designs for new escape rooms. As Vincent commented, they wanted "at least two promising packages which can be further developed into more mature packages [...] Our goal is not about the average quality of all received deliverables, but the best ones".

Once the project was posted on the platform, the crowd members who decided to participate had their own expectations, as revealed in interviews:

The Gamer: "After all, I work for monetary rewards, therefore the chances of winning were important to me. Moreover, I was willing to face challenges. I thought I could learn something new through participation."

The Historian: "Firstly, I was capable of accomplishing the project. It was fun to have a try. In addition, the project offered monetary rewards and extra opportunities, which was appealing."

The Musician: "The monetary rewards, of course, mattered. I am an online worker, looking for feasible

difficult as to affect the consumer's experience). Construction plans consider the practical issues of building the game design and attempt to maximize the consumer's experience.

2 The selected platform was a well-known CS platform, which had been operating in China for 10 years.

${ }^{3}$ Respondents refer to the two phases of the project as online and offline phase. In our analysis we distinguished them as tournamentbased phase and collaborative phase. 
projects. I make a better living this way. However, I did like this project. I did it for fun, learning and altruism. These were the major motivations for my participation."

\subsection{Online (tournament) phase}

During the period when the project was open for submissions, crowd members worked on their designs individually. During this time, they experienced emerging value of an intrinsic nature. As the three winning crowd members described:

The Gamer: "The designing procedure was mentally challenging. It felt good when I was trying hard. I enjoyed the process since I learnt about how to design real escape room games."

The Historian: "I was making efforts to create the game design. As time went by, it felt more and more interesting. Every day it was encouraging to see my progresses. Every day I was able to learn new knowledge. I had a sense of accomplishment."

The Musician: "The game design came into being through hard work. Ifelt a sense of accomplishment and pride."

At the three-week deadline, GamesCo collected contributions submitted by 15 crowd members. To evaluate these 15 submissions 3 members of the management team reviewed each submission individually, and then compared their individual assessments jointly decide on the best 3 submissions. As Vincent, Joe and Max reviewed and assessed submissions, they commented on the value they saw in different submissions, as summarized in Table 3 .

\section{Table 3. Value of Submission (Illustrative Quotes)}

\section{\#4, the Gamer}

- Wonderful! This is a very interesting deliverable. There are integrated storylines. The puzzles and tricks are well embedded in the storylines. I think such a design is worth much more than 1500 CHY. ... Descriptions are very attractive. ... some suggestions on design are given, for example the map puzzle. The only aspect I am worried about is the cost of construction. This is a visionary design, with various imaginary elements. Building a grand environment must involve a huge cost. But I still feel confident. In general, I regard this deliverable very highly. Analyzing this deliverable is a kind of learning. I feel that the designer's logic and control over background elements are worth pondering. I enjoyed it. (Joe)

- This is the most mature design we have had till now. All basic requirements are fulfilled, even beyond my expectation. ... this theme will not have issues related to sales. ... With further development, this design may well be the new gaming room in the new store. (Max)

- Among the four deliverables, I think this one is the best This design is excellent in terms of story theme, storyline, and puzzle design... Working in this industry for a long time, logic becomes fixed. ... This deliverable inspired me a lot in terms of its logic breakthrough. It also made me rethink the direction of Takagism game designs... I think this is an outstanding design. .... (Vincent)

\#5, the Historian

- Of course, there is some value. The logic of the game design is good. ... A breakthrough of this design is that hints accumulated in previous storylines will be used in later storylines. This is creative in its logic. It enhances the fun of playing. ..This game design offers me some inspirations, which could be applied in new game designs." (Vincent)

\section{\#8, the Musician}

- The major advantage and value of this deliverable is the outstanding puzzle design. ... Accomplishing actual construction will not be hard. I think this is one of the top deliverables among all we have received. There are sufficient reasons to further develop it. This could be a very good project. (Joe)

- It is very refreshing, I have never considered or known similar designs. This is a creative design. When I was solving the puzzles, it felt very interesting. .. I am not good at this field, but it is interesting. In addition, the puzzles have operability and are interactive, which requires teamwork. I think this deliverable will be one of the final winners. This is the game design I desire. (Max)

- The design style is relaxed and elegant, and so very different to our previous logic.... This deliverable inspires me a lot in terms of logic breakthrough. It also makes me rethink the direction of escape room game design, it can become more diversified. As a theme, it has a wide range of potential audiences. ... The game design is totally different from existing styles. ... The logic of this deliverable inspires me a lot. ...Another point worth discussing is that this deliverable has the same advantage as a previous deliverable. It is the continuity of hints. Hints gained from previous storylines can be used in later storylines. I think this is an outstanding design. I like it very much. I would definitely further develop this design. (Vincent)

\#9: It has evident flaws: .. It will not be chosen as one of the winners. But it is not absolutely without value. Some of the puzzle designs are inspiring (Joe)

\#10: We have not used such a story theme before. It may enrich our diversity. This could be the value of this deliverable. In terms of puzzle design, I think it is not good enough, and requires more work. (Max)

\#11: The only valuable aspect is that it considers teamwork factors. (Max)

\#14: Some aspects could be transplanted into suitable designs. This is the value I perceive. (Max)

As the PM team decided on the winning deliverables, Vincent reflected on the value they gained from the outcome of the online phase: "The value of the online part was mainly about selecting promising deliverables. \#4 and \#8 are good ones." In addition to the winning 
designs, they indicated value related to the learning. For example, Max elaborated:

"Through analyzing nicely conceived story themes and storylines, and well-designed puzzles and tricks, I have already learnt from the designers' conceptions. Because of the learning process, I felt something new."

In a similar vein Joe explained:

"I feel that value reflects in the quality of deliverables. I think there are at least three kinds of deliverable with three kinds of value. The first type of value, as seen in the \#4 and \#8 deliverables, is the type we desire. It fulfils our needs in terms of quality and creativity, which are core values. The second kind of deliverable has certain aspects that we feel are interesting and inspiring, for example a specific puzzle design. This kind of deliverable is valuable, but as a side value, not a core value. In the last kind, for instance \#1 deliverable, no value was perceived."

\subsection{Offline (collaborative) phase}

4.2.1 Re-evaluating expected outcomes. At the end of the first phase, three top game designs were rewarded, however only the Gamer and the Musician were invited to engage with GamesCo in further design and construction of the actual escape rooms. As Vincent explained: "When it came to the offline part of the project, we believed in the relationship [between us and crowd members]. The growing relationship started working. We chose to trust our candidates; therefore, we did not set any formal contract or fixed agreement. Instead, we offered great flexibility, which encouraged them [the Musician and the Gamer] to innovate and to produce better game designs"

To kick off the second phase, the PM team discussed game designs and working plans with the selected crowd members via webcam meetings. As all three managers (respectively) commented:

"There were great points raised in the meeting; for example, using a unique story theme. His [the Musician's] idea is forward thinking and inspiring. Compared with his pre-design research, it seems that we are too conservative. What we have learned from an external designer is to think outside the box. It is time to rethink our in-house game design processes and get rid of routines". (Joe)

"The conversation was delightful. He [the Gamer] is a lovely guy. He knows how to communicate with people. During the meeting, he was very active and informative... After talking with him, we formed a mutual trust. He is the right person to deliver our game design”. (Max)

"They were great guys. Through webcam meetings we got to know each other better. I think they are easygoing, knowledgeable, and very positive. I felt confident after communicating with them. Especially, the Gamer left me very positive impressions. It was surprising to find that he was very knowledgeable about takagism games". (Vincent)

The Musician and the Gamer, who were invited to collaborate with GamesCo, also saw additional value beyond the monetary reward they received. This additional value was expressed in their sense of appreciation about being selected and invited to collaborate. They also described the potential future value that would result from this collaboration. They commented on their feelings, and the learning opportunities and professional development they expected to gain from participation in the offline phase of the project:

The Gamer: "The manager expressed willingness to further develop my game design. Of course I was happy about it.[...] I was quite motivated because of his encouragement and admiration. It was also a crucial opportunity for me to get some professional direction. This guided my later game designs. "

The Musician: "Talking with professional designers was great. I learned something new about the differences between design and operation. When they criticized one of my puzzle designs, I realized that operability also needs to be considered.[...] "They are nice people. I was encouraged to express my ideas and they respected me. This made me comfortable... I think at that time our relationship became closer. It was valuable in facilitating the effectiveness of our communication."

4.2.2. Interactive development of escape room designs. The offline phase involved several iterations as the internal design team reviewed game designs further developed by the Gamer and the Musician, providing regular feedback until the internal team was satisfied with the design. The intention was to provide guidance, but in such a way that it would not restrict the creativity and ideas of the crowd members. Max commented:

"As the project progressed, we got more surprises from them. We followed their design logic and joined them on their escape room journey. Sometimes they were inspiring. Sometimes they were funny. Good designs could quickly grip me... Their job was to create novel blueprints. Our job was to help them create blueprints and consider whether they could be made into reality... After all, it was for business purposes. We brainstormed, and conducted further research and analysis to examine feasibility and operability. It was a necessary and crucial process which will serve future operations."

Furthermore, the PM team started to note value associated with the newly developed relationships. As Vincent described:

"When it came to the offline phase, we believed in the relationship. Over time, the relationship started 
working. A close relationship made collaboration easy. As we became familiar with each other, we could better understand each other's' language and intentions. When we worked with them and finally accomplished the final designs, I felt emotions of gratitude, closeness, and trust". (Vincent)

The Musician and the Gamer also felt the importance of the relationship as it was emerging during the offline phase of the project:

The Gamer: "We quickly got to know each other and built up mutual trust. That was the foundation for cooperation. My ideas were fully respected and I was encouraged to be creative."

"It was good to expand the network."

"I enjoyed the way they [the team members] managed the project. They did not set any limits to the game design, leaving great room for me to be creative. They trusted me. At the same time, they offered appropriate guidance at the right time." The Musician: "I was motivated by our relationship. It was a kind of payback. They [the team members] trusted me and offered me great opportunities. I really wanted to deliver better designs and, therefore, worked very hard with great patience." "It was a very comfortable cooperation. There were actually no strict rules or regulations. As I just said, I was motivated by our relationship. I felt strongly that I was part of the activity. I was willing to contribute."

Finally, when the designs were completed, the PM team reflected on their level of satisfaction with the final design. The value they expressed at this final, stage of the project was associated with their ability to construct the physical escape room:

"We accomplished two game designs with the candidates. These two designs will be used for our game rooms. I personally like them very much. I am satisfied with the final versions. The two candidates were very thoughtful and smart. Their designs are fluent, logical, and interesting. I am very satisfied with the quality. It was worth spending this amount of money. Later on, our team will systematically analyze them and come up with construction plans. Compared with purchasing copyrights from the American company, it was very cost-effective. Compared with the internal development, we saved time". (Vincent)

When GamesCo made payment to the Musician and the Gamer, Vincent said: "I felt emotions of gratitude, a closer personal relationship, and trust [towards the selected crowd members]".

After the crowd members received their rewards, they shared their reflections on participation in this project: The Gamer: "I think learning under pressure was a valuable experience. I acquired new knowledge, improved my skills and, most importantly, I did it. That is something to be proud of."

"The reward also counts. It was interesting and challenging to work with professional experts in game design while I was the centre of the cooperation".

The Musician: "My design became more mature. I think it could be a good script for a game room. I felt a sense of achievement. I won extra awards for that."

4.2.3. Implementation of the game designs. Both designs were indeed implemented. The Gamer's design was used for the fourth store, which opened in December 2016. The Musician's design was used for an existing local store to replace an old gaming room. The reconstruction was completed in June 2017.

\section{Discussion and contributions}

Guided by our research objectives to understand how value emerges as CS projects unfold, and to identify specific value outcomes over the life of a project, we conducted a longitudinal study of interactions between two key stakeholders - firm and crowd. Our findings (1) reveal the emerging nature of value, and (2) distinguish between value for the firm and value for the crowd, and extent to which they are related (or not). As a limitation, we note that our findings are seen through the eyes of the project winners, whereas future research might further explore the value perceived by all participants. In our case study, the CS initiative was driven by what we coin as "expected value". While crowd submissions at the end of the tournament-based phase were evaluated against this expected value to decide whether (or not) they met these expectation, additional value emerged for the evaluation process itself, as the firm actors went through the submissions. For example, several submissions that did not meet the required criteria to become winners nevertheless gave firm actors some interesting ideas they had not previously thought about (e.g. the basketball trick in submission \#3, and the team factors in \#11). Therefore, the value realized by the firm at the end of the tournament-based phase was more extensive than the initial expected value. Crowd members too were driven by expected value that was associated with extrinsic and intrinsic motivational factors. Two out of three winning crowd members, those who were invited to participate in the next phase and design their ideas further, reflected that value associated with the reward and the invitation went beyond their initial expectations.

After the first phase, firm actors refined their expectations by making more detailed and concrete requirements regarding new escape room designs they were interested in. Then, through interactive and 
collaborative engagement with the selected crowd members, they gained additional value associated with learning from the crowd's expertise (in music and history, respectively), and intrinsic value associated with the trust and inter-personal relationships they developed with these crowd members. Similarly, the selected crowd members expressed appreciation of the value associated with learning about game design, gaining new skills important for their professional development, and a high level of satisfaction with the relationship developed with managers of GamesCo.

This emerging nature of value - from the initial, expected value that is then refined and complemented by value associated with learning and the developing relationship as the parties interact - is evident for both firm and crown stakeholders. However, it is important to distinguish between value for the firm and value for the crowd, which are essentially different when the two parties engage in a CS project - the crowd is expecting extrinsic and intrinsic value, while the firm is expecting a business-related value. However, when the crowdsourcing project is designed to include collaborative engagement with crowd members (e.g. offline phase of the Games design project), the value that emerges through the interactions between the stakeholders is a shared value that demonstrates mutual benefits and appreciation.

Moreover, our study demonstrates that CS could be designed to rely on value creation or value co-creation. Value creation is evident in tournament-based CS, as crowd members work independently to create value for the firm. In the end, the firm decides whether the value has been created or not, and selects winners to be rewarded for value they have created. Value co-creation is, however, a joint endeavour. It implies an element of collaboration between the parties through which value is created jointly (i.e. co-created). Thus, it is only in collaborative CS projects that value is co-created through interactions between the different stakeholders. In our study, we observed value co-creation during the second phase of the Games Design project. In the literature there are examples of CS projects where crowd members collaborate between themselves and/or with the firm. The Treadless example mentioned earlier also illustrates value co-creation, as crowd members vote for their favourite designs.

In Table 4 we summarize firm and crowd perspectives on value during different phases of the CS project. This table distinguish between different dimensions of the value. In Table 5 we illustrate how value is emerging through what we coin as value-related processes: starting from value expectation that firm and crowd members do individually, followed by value creation when crowd is working individually creating value (or rather hoping that client will recognize value in their submission), and/or value co-creation which relies on interactive, collaborative efforts of between firm and crowd stakeholders. CS projects may include only value creation or value co-creation processes, or both (as in our case study). Value appreciation process is associated with the final stage of a CS project when all stakeholders reflect on the value gained through CS. While firm and crowd reflect on their own value, they also appreciate shared value from the CS experience.

\subsection{Theoretical Contribution}

The main contribution of this study is to the growing body of the crowdsourcing literature. We offer a process perspective on emerging value and distinguish between value for firm and value for crowd (as depicted in Figure 1). In doing so, we address an observed gap in the literature, which lacks an overarching understanding of crowdsourcing value creation process. Given that the Games Design project involved two different CS models - tournament-based and collaborative - we were able to compare and contrast similarities and differences between the two models in terms of implications for value (co-)creation, and to see how they are related when combined in the same CS initiative.

In line with the first objective of our work, we studied the process of value creation and transitions from valuein-exchange to value co-creation over the life of the project. During the tournament-based phase, value-inexchange took the form of monetary value expectations (by the crowd) in exchange for game ideas (for the firm). Since value-in-exchange is set by the project parameters prior to initiating the project, there is a potential challenge in setting the monetary amount as the client firm cannot foresee the true value of the ideas they might receive. During this phase, stakeholders experienced value-in-use that took the form of some (limited) learning outcomes for both firm and crowd. However, in comparison to the value-in-use that was experienced in the next, collaborative phase, value-inuse during the tournament-based phase was not so significant due to a definition of project parameters that limited interactions.

In the second, collaborative phase, value-in-exchange was also associated with monetary reward. However at this stage, the firm had a better idea of what they would receive (i.e. detailed game designs), so the exchange was more accurately estimated. The selected crowd members also had a good understanding of what was required from them in exchange for the (guaranteed) reward. Therefore in this phase, value-in-exchange closely reflected the value expectations held by each party prior to engaging in the collaborative work. We therefore find that the value-in-exchange for the collaborative CS phase was more accurate than for the tournament-based phase, due to some learning 
experiences on both sides. During the collaborative phase, there was significant value-in-use in terms of the learning and relationship development that we previously noted. The interactive nature of this phase enabled true value co-creation where value-in-use was mutual and shared between the parties.

In line our second objective to add a temporal dimension to this body of literature and track specific value outcomes as they unfold over the life of the project, in Figure 1, we depict our findings and attempt to make them applicable to various CS contexts. This figure illustrates how value transforms from expected to emergent and then to realized, building on the notion of value-in-exchange and value-in-use experienced by the project stakeholders.

Table 4. Value Dimensions over Time: Firm and Crowd perspectives

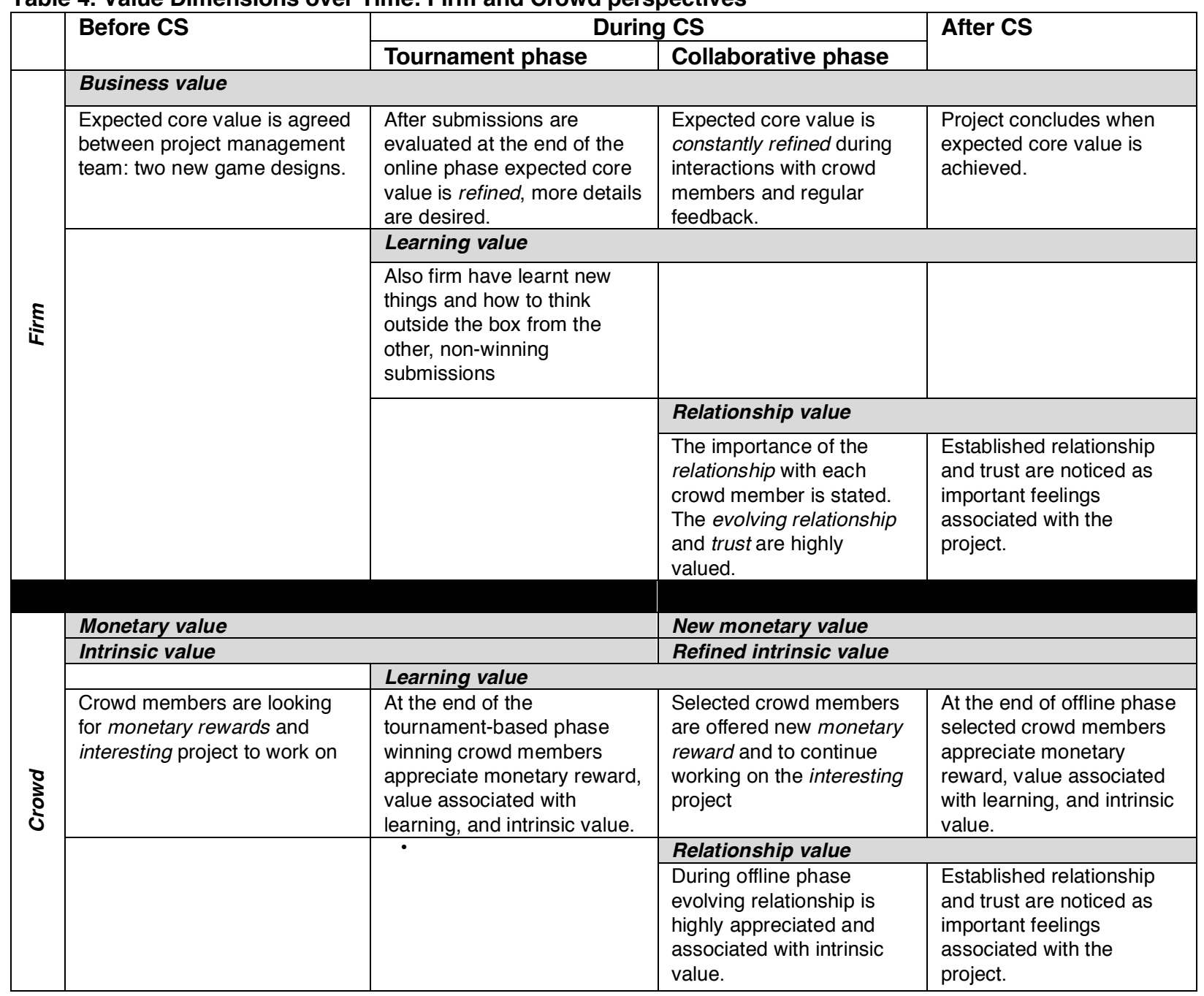

Table 5. Value-related Processes over Time

\begin{tabular}{|l|l|l|l|l|}
\hline \multicolumn{1}{|c|}{} & Before & Tournament phase & Collaborative phase & After \\
\hline $\begin{array}{l}\text { Firm vs crowd } \\
\text { relationship } \\
\text { with the value }\end{array}$ & $\begin{array}{l}\text { Each party has own } \\
\text { expectations regarding } \\
\text { the value expected from } \\
\text { participation in } \\
\text { crowdsourcing }\end{array}$ & $\begin{array}{l}\text { Crowd members work } \\
\text { individually creating } \\
\text { something that would be } \\
\text { (not) considered of value } \\
\text { by the firm }\end{array}$ & $\begin{array}{l}\text { Crowd members work } \\
\text { together with the firm co- } \\
\text { creating value that meets } \\
\text { firm's evolving } \\
\text { expectations. }\end{array}$ & $\begin{array}{l}\text { Each party evaluate } \\
\text { (and appreciate) } \\
\text { value(s) gained from } \\
\text { the project }\end{array}$ \\
\hline $\begin{array}{l}\text { Value-related } \\
\text { process }\end{array}$ & $\begin{array}{l}->\text { Value expectation } \\
\text { (crowd and firm, } \\
\text { independently) }\end{array}$ & $\begin{array}{l}->\text { Value creation } \\
\text { (crowd for firm, whether } \\
\text { the value was created or } \\
\text { not depends on firm's } \\
\text { evaluation) }\end{array}$ & $\begin{array}{l}->\text { Value co-creation } \\
\text { (crowd with firm, through } \\
\text { interactive and } \\
\text { collaborative efforts) }\end{array}$ & $\begin{array}{l}->\text { Value } \\
\text { appreciation } \\
\text { (crowd and firm } \\
\text { individually and } \\
\text { jointly) }\end{array}$ \\
\hline
\end{tabular}


Figure 1. A Process Perspective on Emerging Value in Tournament-based and collaborative crowdsourcing

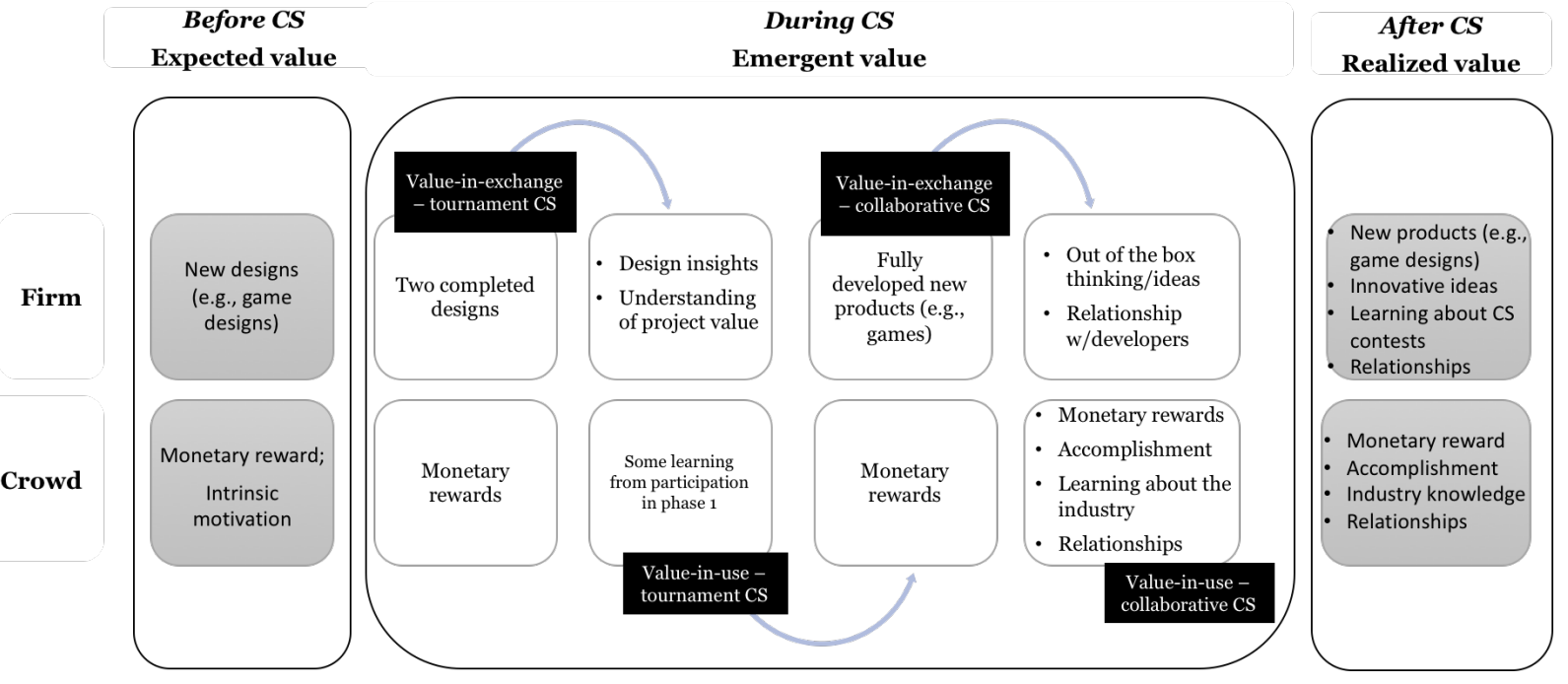

\section{References}

[1] Howe, J. (2006). The Rise of Crowdsourcing. Wired Magazine, 14.

[2] LaToza, T. D. \& van der Hoek, A. 2016. Crowdsourcing in Software Engineering: Models, Motivations, and Challenges. IEEE Software, 33: 74-80

[3] Poetz, M. K. \& Schreier, M. 2012. The Value of Crowdsourcing: Can Users Really Compete with Professionals in Generating New Product Ideas? The Journal of Product Innovation Management, 29: 245-256

[4] Erkinheimo, P., Jussila, J., \& Kärkkäinen, H. 2015. Lean start-up companies by means of crowdsourcing. Journal of Innovation Management, 3: 17-20

[5] Fréry, F., Lecocq, X., \& Warnier, V. 2015. Competing With Ordinary Resources. MIT Sloan Management Review, 56: 6977

[6] Kohler, T. 2015. Crowdsourcing-Based Business Models: How to Create and Capture Value. California Management Review, 57:63-84

[7] Vargo, S. L., Maglio, P. P., \& Akaka, M. A. 2008. On value and value co-creation: A service systems and service logic perspective. European Management Journal, 26: 145-152

[8] Nevo, S. \& Wade, M. 2010. The formation and value of ITenabled resources: Antecedents and consequences of synergistic relationships. MIS Quarterly, 34: 163-183

[9] Afuah, A., \& Tucci, C. L. 2012. Crowdsourcing as a Solution to Distant Search. Academy of Management. The Academy of Management Review, 37: 355-375

[10] Chiu, C.-M., Liang, T.-P., \& Turban, E. 2014. What can crowdsourcing do for decision support? Decision Support Systems, 65: 40-49

[11] Nishikawa, H., Schreier, M., Fuchs, C., \& Ogawa, S. 2017. The Value of Marketing Crowdsourced New Products as Such: Evidence from Two Randomized Field Experiments. Journal of Marketing Research, 54: 525-539

[12] Glaeser, E. L., Hillis, A., Kominers, S. D., \& Luca, M. 2016. Crowdsourcing City Government: Using Tournaments to Improve Inspection Accuracy. The American Economic Review, 106:114-118

[13] Jame, R., Johnston, R., Markov, S., \& Wolfe, M. C. 2016. The Value of Crowdsourced Earnings Forecasts. Journal of Accounting Research, 54:1077-1110
[14] Bonabeau, E. 2009. Decisions 2.0: the Power of Collective Intelligence. MIT Sloan Management Review, 50: 45-52

[15] Ye, H. \& Kankanhalli, A. 2013. Leveraging Crowdsourcing for Organizational Value Co-Creation. Communications of the Association for Information Systems, 33: article 13.

[16] Gatzweiler, A., Blazevic, V., \& Piller, F. T. 2017. Dark Side or Bright Light: Destructive and Constructive Deviant Content in Consumer Ideation Contests. The Journal of Product Innovation Management, 34:772-789

[17] Deng, X. \& Joshi, K. D. 2016. Why Individuals Participate in Micro-task Crowdsourcing Work Environment: Revealing Crowdworkers' Perceptions. Journal of the Association for Information Systems, 17:648-673

[18] Frey, K., Lüthje, C., \& Haag., S. 2011. Whom should firms attract to open innovation platforms? The role of knowledge diversity and motivation. Long Range Planning, 44:397-420

[19] Morgan, J. \& Wang, R. 2010. Tournaments for Ideas. California Management Review, 52:77-97

[20] Boons, M., Stam, D., \& Barkema, H. G. 2015. Feelings of Pride and Respect as Drivers of Ongoing Member Activity on Crowdsourcing Platforms. The Journal of Management Studies, 52: 717-741

[21] Gol, E. S., Stein, M-K., \& Avital, M. 2019. Crowdwork Platform Governance toward Organizational Value Creation. The Journal of Strategic Information Systems

[22] Hofstetter, R., Zhang, J.Z., \& Herrmann, A., 2018. Successive Open Innovation Contests and Incentives: Winner-Take-All or Multiple Prizes? Journal of Product Innovation Management, 35: 492-517

[23] Langley, A. 1999. Strategies for Theorizing from Process Data. Academy of Management Review, 24: 691710.

[24] Langley, A., Smallman, C., Tsoukas, H., \& Van de Ven, A. 2013. Process Studies of Change in Organization and Management: Unveiling Temporality, Activity, and Flow. Academy of Management Journal, 56: 1-13

[25] Gioia, D. A., Corley, K. G. \& Hamilton, A. L. 2013. Seeking Qualitative Rigor In Inductive Research Notes on The Gioia Methodology. Organizational Research Methods, 16: 15-31. 